\title{
Developmental Regulation of Ganglioside Antigens Recognized by the JONES Antibody
}

\author{
Burkhard Schlosshauer, ${ }^{a}$ Andrew S. Blum, ${ }^{1}$ Rosalia Mendez-Otero, ${ }^{b}$ Colin J. Barnstable, ${ }^{1}$ and \\ Martha Constantine-Paton \\ Department of Biology, Yale University, New Haven, Connecticut 06511, and 'Laboratory of Neurobiology, The \\ Rockefeller University, New York, New York 10021
}

The JONES monoclonal antibody has been immunocytochemically associated with regions of the developing rat brain where cell and axon migrations are occurring (MendezOtero et al., 1986, 1988). In the present study the antigens recognized by the JONES antibody were analyzed in a variety of brain regions and at developmental ages selected to correspond to the preceding immunocytochemical observations.

In accordance with earlier results from retina, JONES binding could not be detected in SDS gels from developing brain. Binding of the antibody was, however, prominent in chloroform/methanol extracts of the same tissues, and it was completely removed from tissue sections by brief chloroform/methanol treatment. Enzymatic analyses of chloroform/methanol extracts indicated that the JONES epitope was sensitive to neuraminidase but insensitive to proteases. Overlay assays on developed high-performance thin-layer chromatographic plates (HPTLC) indicate that in all regions the JONES epitope resides on 2 or 3 ganglioside bands, depending on the age examined. These bands migrate between ganglioside standards GD1 $a$ and GM2 on HPTLC plates and have been designated GJ1, GJ2, and GJ3, with the higher number designating the more rapidly migrating species. Occasionally, additional bands migrating in the range of polysialogangliosides were observed.

The pattern of expression of GJ species was studied in forebrain, retina, and cerebellar tissue taken from embryonic day 18 (E18), postnatal day 0 (P0), P7, P14, and adult animals. Both region-specific differences in the relative prominence of each band and stage-specific differences in the total amount of the JONES gangliosides were detected. The stage-specific differences in the amount of JONES antigens

\footnotetext{
Received Mar. 13, 1987; revised Aug. 10, 1987; accepted Aug. 14, 1987.

We thank Dr. Robert Yu for his advice during the execution of this project and for his helpful comments on the manuscript. We also wish to thank Daniela Bonafede for her help during the revision of the manuscript and Leena Kalghati and Lisam Schwarz for excellent technical assistance. This work was supported by Biomedical Research Support Grant R07015 to Yale University, a NIH Grant NS 20483 to C.J.B., a Deutsche Forschungsgemeinschaft Fellowship to B. S., a MSTP Grant GM07739 Award to A. S. Blum, and a Fulbright/Capes Fellowship Award and a CNPq Brazilian Fellowship to R.M.-O.

Correspondence should be addressed to Dr. Martha Constantine-Paton, Department of Biology, Yale University, Kline Biology Tuwer, P.O. Bux 6666, New Haven, CT 06511.

a Present address: Max-Planck-Institut für Entwicklungsbiologie, Spemannstr. 35/I, D-7400 Tübingen, Federal Republic of Germany.

b Permanent address: Universidade do Estado do Rio de Janeiro, Instituto de Biologia, Rio de Janeiro, RJ 20551 Brazil.

Copyright (C) 1988 Society for Neuroscience $0270-6474 / 88 / 020580-13 \$ 02.00 / 0$
}

are well correlated with the developmental periods of maximal cell migration in each region. While the JONES gangliosides are most prominent in forebrain before birth, in retina they are most prominent during the first 2 postnatal weeks. In cerebellum, JONES antigen expression is more pronounced during the 2 periods of cell migration in this tissue. In retina, the more rapidly migrating GJ3 band was the most prominent band at all stages examined, and this same band is retained in the adult. In cerebellum and forebrain GJ3 is also the most pronounced band during development. However, in contrast to the retina, the more slowly migrating $\mathrm{GJ} 1$ band is retained in adult forebrain and cerebellum.

A variety of non-brain tissues have also been examined for the presence of the JONES antigens. The GJ1 and GJ3 bands are prominent in E18 dorsal root ganglia, and dot assays reveal their presence in chloroform/methanol extracts of P2 and adult kidney and P2 adrenal glands. The same assays failed to reveal any JONES antigenicity in P2 thymus, lung, heart, stomach, spleen, liver, intestine, and skeletal muscle.

Our results indicate that the JONES antibody recognizes a sialic acid-bearing carbohydrate epitope on a small subset of gangliosides in all brain regions examined. In the developing brain the biochemical localization is fully consistent with a role for these antigens in selective cell motility. The biochemical differences in JONES binding in the adult as well as the presence of the antigens in kidney cautions, however, that these same molecules may be associated with quite different functions in non-neural regions or in the adult brain.

There is increasing evidence that the communication between a neural cell and its environment can be influenced by membrane-associated glycolipids. Among the glycolipids, gangliosides have attracted particular attention in the context of neurogenesis (Hakamori, 1981). These small sialic acid-bearing molecules have specific patterns of expression in different brain regions and are under rigid developmental control (Dreyfus et al., 1976; Rosner, 1980b; Willinger and Schachner, 1980; HenkeFahle, 1983; Grunwald et al., 1985; Yamamoto et al., 1985). They have also been implicated in a variety of developmental functions. For instance, antiganglioside antibodies can inhibit sprouting from cultured retinal explants, dorsal root ganglia and PC1 2 cells (Schwartz and Spirman, 1982; Spirman et al., 1982; Gorio ct al., 1985) and addition of gangliosides accelerates ax- 
onal sprouting and regeneration both in vivo and in vitro (Sparrow and Grafstein, 1982; Gorio et al., 1983; Tsuji et al., 1983; Toffano et al., 1984). Gangliosides have been associated with regions of neuronal and glial proliferation (Goldman et al., 1984; Levine et al., 1984) and with the differentiation of neuronal and glial cells in culture (Seifert, 1981; Hefti et al., 1985). Finally, various investigations of cell-cell as well as cell-substratum adhesion have suggested that gangliosides may modulate contact-mediated cell interactions (Barbera et al., 1973; Barbera, 1975; Marchase, 1977; Blackburn et al., 1986; Cheresh and Klier, 1986; Cheresh et al., 1986; Thompson et al., 1986).

We have identified the monoclonal antibody JONES using an immunological approach to define molecules whose appearance would correlate with major events in neurogenesis. The epitope recognized by this antibody is maintained as a distinct dorsoventral gradient within the rat retina during the period when the topographic central projections of retinal ganglion cells are being established within the brain (Constantine-Paton et al., 1986). The retinal antigen was extractable into organic solvents. It migrated as a band in the region of gangliosides GM1 and GM2 on high-performance thin-layer chromatography (HPTLC) plates developed in a chloroform/methanol solvent system, and antibody reactivity to blots of these HPTLC plates was completely abolished by pretreatment of the retinal extracts with neuraminidase (Constantine-Paton et al., 1986).

In the preceding paper we presented immunocytochemical evidence that the epitope recognized by the JONES antibody is selectively associated with regions of cell and axon motility in the developing rat CNS (Mendez-Otero et al., 1988). In the present report we have used biochemical methods to examine the distribution of this epitope in the same CNS regions at the same stages of development. We present evidence that JONES recognizes the same 2 or 3 ganglioside bands in all regions of the developing brain that we have examined. These bands are regulated individually during development in the retina, forebrain, and cerebellum in a pattern consistent both with our immunocytochemical findings and with the developmental periods of cell and axon motility. Our results indicate that these gangliosides are differentially associated with cell and axon migrations in the developing brain and suggest that they may be involved in the specificity of these processes. A preliminary report of this work has appeared previously (Schlosshauer et al., 1986).

\section{Materials and Methods}

Animal surgery. Adult animals were sacrificed either by cervical dislocation or by Nembutal overdose prior to dissection. Fetal tissue was obtained as described previously (Mendez-Otero et al., 1988). Both Long-Evans and Sprague-Dawley rats were used interchangeably for these analyses, and in all cases tissue from retina, cerebellum, and forebrain was taken from each animal, so that slight differences in age between different animals or different litters would not bias our comparisons of different regions.

SDS gel analysis. Entire brains were dissected from embryonic day (E) 20 fetuses, homogenized in ice-cold isotonic sucrose and fractionated by differential centrifugation into a cytoplasmic and membrane fraction (Barnstable, 1982). Additional brains from the same litter were rapidly homogenized in hot SDS sample buffer to limit proteolytic degradation. Approximately $200 \mu \mathrm{g}$ per lane of the crude brain homogenate, the soluble fraction and the membrane pellet were run on $10 \%$ SDS-polyacrylamide gels under reducing conditions (Laemmli, 1970). Blotting and antibody labeling of blots were carried out as described previously (Fekete and Barnstable, 1983). Monoclonal antibodies that recognized tubulin or intermediate filament proteins were incubated with duplicate lanes as positive controls for the Western blot analysis.
Extraction of tissue sections. Sections of postnatal day $(\mathrm{P}) 0$ cerebellum and forebrain were exposed to chloroform/methanol (1:2) for $5 \mathrm{~min}$. Sections were subsequently dried, rehydrated, and reacted for indirect immunofluorescence or stained with toluidine blue as described previously (Mendez-Otero et al., 1988).

Ganglioside isolation. Neural and non-neural tissues of selected developmental stages were dissected for ganglioside purification, which was performed either by the Folch method on a macroscale (Folch et al., 1957) or on a microscale (Saito et al., 1985; H. Rosner, personal communication). The recovery of gangliosides was found to be comparable with the 2 methods. Ganglioside concentration was mcasured by the method of Svennerholm (1957), using a sialic acid standard, or by scanning developed HPTLC plates (Merck) with ganglioside standards in one of the lanes. Standards were a generous gift of Dr. R. Yu, and purified GM1 was generously supplied by Dr. H. Rosner.

High-performance thin-layer chromatography. Chromatography was performed for $55 \mathrm{~min}(10 \mathrm{~cm}$ plate height) or for $165 \mathrm{~min}(20 \mathrm{~cm}$ plate height) at room temperature with a solvent system of chloroform $/ \mathrm{meth}$ anol/ $0.2 \%$ aqueous $\mathrm{CaCl}_{2}(50: 45: 10)$. In some cases the dual solvent system ("DE") was used as described in Rosner (1980a). In most cases, each individual sample was applied in 3 different concentrations onto HPTLC plates; this allowed us to detect even low amounts of JONES gangliosides, although too high concentrations resulted in retarded migration and bending of the bands. For immunological overlay assays, air-dried plates were treated at room tempcraturc with $0.4 \%$ polyisobutylmethacrylate in hexane/chloroform (Saito et al., 1985). Nonspecific binding sites were blocked with $1 \%$ BSA in PBS for $45 \mathrm{~min}$; the plates were then incubated with purified IgM JONES antibody [20 $\mu \mathrm{g} / \mathrm{ml}$ PBS with $10 \%$ fetal calf serum (FCS)] for $16 \mathrm{hr}$ at $4^{\circ} \mathrm{C}$, washed 5 times with PBS, followed by incubation with an HRP-labeled goat anti-mouse antibody (1:200, Jackson) in 10\% FCS in PBS for $5 \mathrm{hr}$ at room temperature, washed again 5 times with PBS, and reacted with chloronaphthol. Staining of HPTLC plates was performed with the resorcinol reagent according to Svennerholm (1957).

Dot assays used the same ganglioside preparation procedure. These extracts were dried onto HPTLC plates and processed for immunoreactivity as above.

In order to obtain an estimate of the relative changes in the amount of JONES gangliosides with increasing developmental age, HPTLC plates labeled by the overlay assay were scanned with a scanning densitometer. Peak areas were normalized across different plates, and the sum of the major JONES bands of the E18 forebrain sample was arbitrarily set at $100 \%$.

Enzymatic treatments. Crude ganglioside fractions $(25 \mathrm{ng}$ sialic acid per well) were dried onto PVC microtiter plates. The plates were incubated with enzyme-containing solutions $(50 \mu \mathrm{m} /$ well) for 1 or $3 \mathrm{hr}$ at $37^{\circ}$. Protease (Sigma) treatments were carried out at a concentration of $1 \mathrm{mg} / \mathrm{ml}$ in $50 \mathrm{~mm}$ Tris/ $\mathrm{HCl}, \mathrm{pH} 7.4$. Protease activity in this assay was verified by the attenuation of monoclonal antibody rho-1D4, which recognizes a C-terminal protein determinant of rhodopsin (Molday and MacKenzie, 1983; gift of D. Hicks), binding to adult rat retinal membranes. Neuraminidase (Sigma, C. perfringens Type X, $5 \mathrm{mU} /$ well) treatment was performed in $0.1 \mathrm{~m}$ sodium acetate, $\mathrm{pH} 5.5$, containing $0.1 \%$ $\mathrm{CaCl}_{2}$. Following incubation, the enzyme solutions were decanted, the wells washed with PBS containing $0.1 \%$ BSA, incubated with JONES antibody and, after subsequent washes, with iodinated ( $\left.{ }^{125} \mathrm{I}\right)$ rabbit antimouse antibody (Barnstable, 1982). After washing as before, the wells were cut and counted. For further purification of neuraminidase, the enzyme (Type $\mathrm{X}$ from $C$. perfringens, Sigma) was dissolved in $20 \mathrm{~mm}$

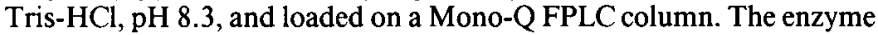
was eluted with a linear gradient of $0-1 \mathrm{M} \mathrm{NaCl}$ at a flow rate of $1 \mathrm{ml} /$ min. The $0.5 \mathrm{ml}$ fractions collected were assayed separately for JONES degrading activity and neuraminidase activity. Neuraminidase activity was assayed by measuring sialic acid released from a mixed ganglioside preparation using a thiobarbituric acid assay (Warren, 1959) with $N$-acetylneuraminic acid as standard.

Cell cultures. Cells from freshly dissected E19 rat forebrain were dissociated as below and plated on poly(L-lysine)-coated cover slips (100 $\mu \mathrm{g} / \mathrm{ml}$, Sigma). After culturing for $1 \mathrm{~d}$ in supplemented RPMI medium (RPMI, Gibco; $10 \%$ fetal calf serum, Gibco; 2 mm glutamine, Sigma), cells were incubated for an additional $30 \mathrm{~min}$ with purified JONES antibody $(20 \mu \mathrm{g} / \mathrm{ml})$. For immunocytochemistry, cells were washed with PBS, fixed in $4 \%$ paraformaldehyde for $10 \mathrm{~min}$ at $20^{\circ} \mathrm{C}$, rinsed, and incubated with rhodamine-labeled goat anti-mouse antibody (Cappel, 1:50 dilution in PBS with 5\% goat serum). 
Table 1. Effect of enzymatic treatments of perinatal retinal gangliosides on JONES antibody binding

\begin{tabular}{lcc} 
& \multicolumn{2}{c}{ \% Control Binding } \\
\cline { 2 - 3 } Enzyme & Reaction time (hr) \\
\cline { 2 - 3 } & 1 & 3 \\
\hline Trypsin & $90 \pm 13.5$ & $87 \pm 13.7$ \\
Pronase & $108 \pm 4.8$ & $98 \pm 7.3$ \\
Collagenase & $94 \pm 14.7$ & $112 \pm 23.0$ \\
Neuraminidase & $34 \pm 1.1$ & $39 \pm 1.6$
\end{tabular}

Enzyme treatments and subsequent radioimmunoassays were performed in duplicate as in methods. Specific JONES binding was determined by subtracting the contribution of nonspecific antibody binding. All values are expressed as a percentage of specific binding to untreated samples.

Cell perikarya isolation. For cell preparations, neural tissue was dissected under sterile conditions, incubated for $20 \mathrm{~min}$ at $37^{\circ} \mathrm{C}$ with 1 $\mathrm{mg} / \mathrm{ml}$ trypsin (Gibco, 1:250) in PBS, washed 3 times with PBS, and triturated in PBS containing $50 \mu \mathrm{g} / \mathrm{ml}$ DNase I (Sigma). Large tissue fragments were removed by $1 \times g$ sedimentation. Remaining debris was removed by brief centrifugation ( $30 \mathrm{sec}, 0-200 \times g)$, and the cells in the supernatant were pelleted by centrifugation for $6 \mathrm{~min}$ at $200 \times$ $g$. The cell pellet was washed by repetitive trituration and centrifugation steps as above until a homogeneous suspension of cell perikarya was obtained.

\section{Results}

\section{Characterization of the JONES antigen}

\section{Tissue extracts}

Immunoblots made from SDS-polyacrylamide gels of soluble proteins, membrane pellets, or whole homogenates of E20 rat forebrain failed to demonstate JONES immunoreactivity. This result is fully consistent with previous results demonstrating the absence of JONES immunoreactivity in Western blots of fetal retina (Constantine-Paton et al., 1986).

The further characterization of the JONES antigen in the fetal rat CNS was carried out in 2 steps. First, tissue sections of P0 forebrain and cerebellum, adjacent to sections that showed high concentrations of JONES antigen (Mendez-Otero et al., 1988), were treated with chloroform/methanol and reacted with the JONES antibody for indirect immunofluorescent localization of the antigen. This treatment completely abolished JONES immunoreactivity despite the fact that similarly treated sections subsequently stained with toluidine blue showed normal histology. It therefore appears from both the Western blot and the tissue extraction assay that the majority, if not all, of the molecules carrying the JONES epitope was extracted from developing rat brain by the chloroform/methanol treatment.

\section{Enzyme sensitivity}

The second step was to analyze the material removed from the tissue by the organic solvent system. Ganglioside extracts of fetal tissue were exposed to a variety of enzymes. All extracts were made from P0-P3 neural retina because of the accessibility of this region and the high antigen concentrations demonstrated by immunocytochemistry.

As can be seen in Table 1, neither collagenase nor trypsin decreased JONES binding. Even pronase, a broad-spectrum protease, did not prevent antibody binding. Both trypsin and pronase were shown to be active by the virtually complete removal of rho-1D4 binding to protease-treated adult rat retinal membranes. Neuraminidase treatment of the retinal extracts, on the other hand, reduced immunoreactivity to approximately $35 \%$

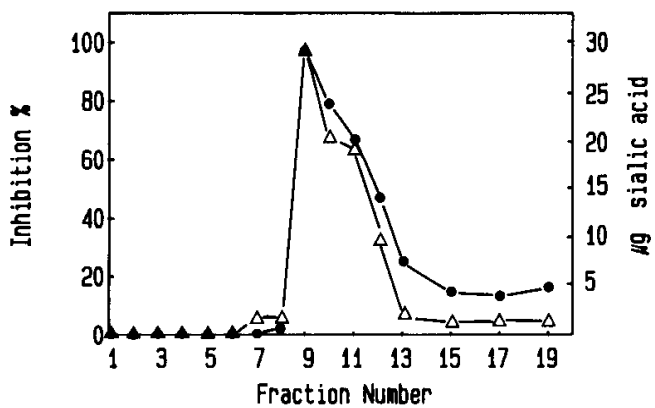

Figure 1. Coelution of neuraminidase activity and removal of JONES binding activity in neuraminidase fractionated by FPLC. Ganglioside samples dried onto microtiter plates were treated with the neuraminidase fractions eluted from a Mono-Q FPLC column. Released sialic acid was measured by the thiobarbituric acid method and remaining JONES immunoreactivity was measured by an indirect radioactive binding assay. The curves are plotted as percentage inhibition of JONES binding and micrograms sialic acid released for each fraction tested. Peak activities both occur in the same fraction and the shape of the curves are very similar, indicating that the same activity is responsible for both effects. Filled circle represents the inhibition of JONES antibody binding; open triangle represents sialic acid release.

of the initial value (Table 1). To confirm that the reduction in JONES binding was not the result of contamination in the commercially available enzyme, the neuraminidase was further fractionated on an FPLC Mono-Q column and the fractions were tested for their ability to reduce JONES binding and for neuraminidase activity. As can be seen in Figure 1, there was almost complete coincidence of the 2 activities, which strongly implies that a sialic acid residue is an essential part of the JONES epitope.

\section{Thin-layer chromatography}

Ganglioside extracts from various regions of the fetal rat nervous system were separated by TLC and assayed for JONES antigenicity by overlaying the JONES mab and visualizing its binding position directly on the plate using an HRP-labeled second antibody, followed by chloronaphthol reaction.

Depending on the developmental stage and the tissue chosen for analysis, one major and usually one or two minor ganglioside bands were detected (Fig. 2). The upper band, with the fastest migration rate in the chloroform $/$ methanol $/ \mathrm{CaCl}_{2} / \mathrm{H}_{2} \mathrm{O}$ solvent system used, was located between GM1 and GM2. The lower band was located above GDla approximately in the region of GD3. In some instances, a third band migrated slightly above the slowest JONES positive band. For convenience, we have labeled these bands by following the general principles of nomenclature for gangliosides established by Svennerholm (1980) but replacing the sialic acid designation with the antibody designation. Thus, we will refer to the three JONES immunoreactive bands as GJ 1, GJ2, and GJ3, indicating the slowest (lowest) through the most rapidly migrating (highest) band, respectively.

In some experiments, particularly when gangliosides were extracted from adult tissue, additional bands migrating below the developmentally prominent bands, between GDla and GT1b, could be observed (for example, see some lanes in Fig. 7). However, these bands were not obtained reproducibly.

\section{Developmental expressions of JONES gangliosides}

\section{Retina}

Figure 3 shows HPTLC overlay assays of JONES binding to retinal extracts of increasing age run on the same plate. It can 
be seen that embryonic retina (E18) showed 2 bands, namely, a lightly reactive GJ1 band and a more intensely reactive GJ3 band. Four days later, at birth ( $\mathrm{P} 0)$, a similar pattern was present, and this was maintained through the first postnatal week. During this period the concentration of JONES immunoreactive gangliosides reached a maximum. At P14 a decrease in the concentration of JONES binding gangliosides was observed, and this lower level was maintained until adulthood. At all stages examined, the GJ3 band was always much more prominent than the GJ1 band. The GJ1 band was, in fact, barely discernible in HPTLC overlay assays when ganglioside preparations from retinas older than 1 week postnatal were analyzed.

\section{Cerebellum}

The pattern of JONES immunoreactive gangliosides expression in cerebellum showed distinct differences compared with retina both in the total amount of JONES binding and in the bands that predominated at particular developmental ages. The highest concentration of JONES immunoreactivity was found at embryonic stages. This can be seen on the HPTLC plate of Figure $4 a$, where the immunostaining at E18 is clearly more intense than at P0. The proportion of JONES immunoreactive gangliosides in the extracts rose again briefly in the first postnatal week, but after the second postnatal week it became reduced and reached the lowest level in the adult brain.

In addition to these changes in the proportion of JONES immunoreactivity relative to total gangliosides, the relative proportion of JONES binding in each of the 3 bands also varied in tissue taken at different developmental stages. At E18, both GJ1 and GJ3 were present, although GJ3 was the more abundant. During the second postnatal week, the GJ3 band decreased in intensity and the GJ1 band increased in intensity such that GJ1 was the most pronounced JONES immunoreactive band in the P14 and adult cerebellum (Fig. 4c). A transient band of intermediate migration, GJ2, could be first detected at P0, but at this stage it was much lighter than either of the other 2 bands. In cerebellar tissue taken at $\mathrm{P} 7$ this band was pronounced and essentially overshadowed the considerably weakened staining in the position of the GJ1 band (Fig. 4b). At later stages, GJ2 was drastically reduced.

\section{Forebrain}

The expression of JONES immunoreactive gangliosides in the developing forebrain is shown in Figures 5 and 6 . The pattern of JONES binding in ganglioside extracts from forebrain resembled that of the cerebellum rather than that of the retina: the highest proportion of JONES binding was found at embryonic stages, and with development the intensity of the GJ3 band decreased and that of the GJ1 band increased (Fig. 5).

Figure 6 illustrates the results of a semiquantitative evaluation of overlay assays from forebrain HPTLC plates. The analysis revealed that within $3 \mathrm{~d}(\mathrm{E} 18-\mathrm{P} 0)$ the proportion of JONES gangliosides declined by more than $50 \%$. This forebrain decrease in total JONES ganglioside expression continued through the postnatal period, resulting in a total JONES ganglioside expression equal to $7 \%$ of the embryonic value by P14. The adult forebrain showed a slight increase over the P14 level to $13 \%$ of the embryonic value.

To compare these changes in JONES immunoreactivity with the overall changes in forebrain ganglioside levels, as illustrated in Figure $5 a$, the same tissue samples were run in an additional experimental series and stained with resorcinol (Fig. $5 b$ ). The

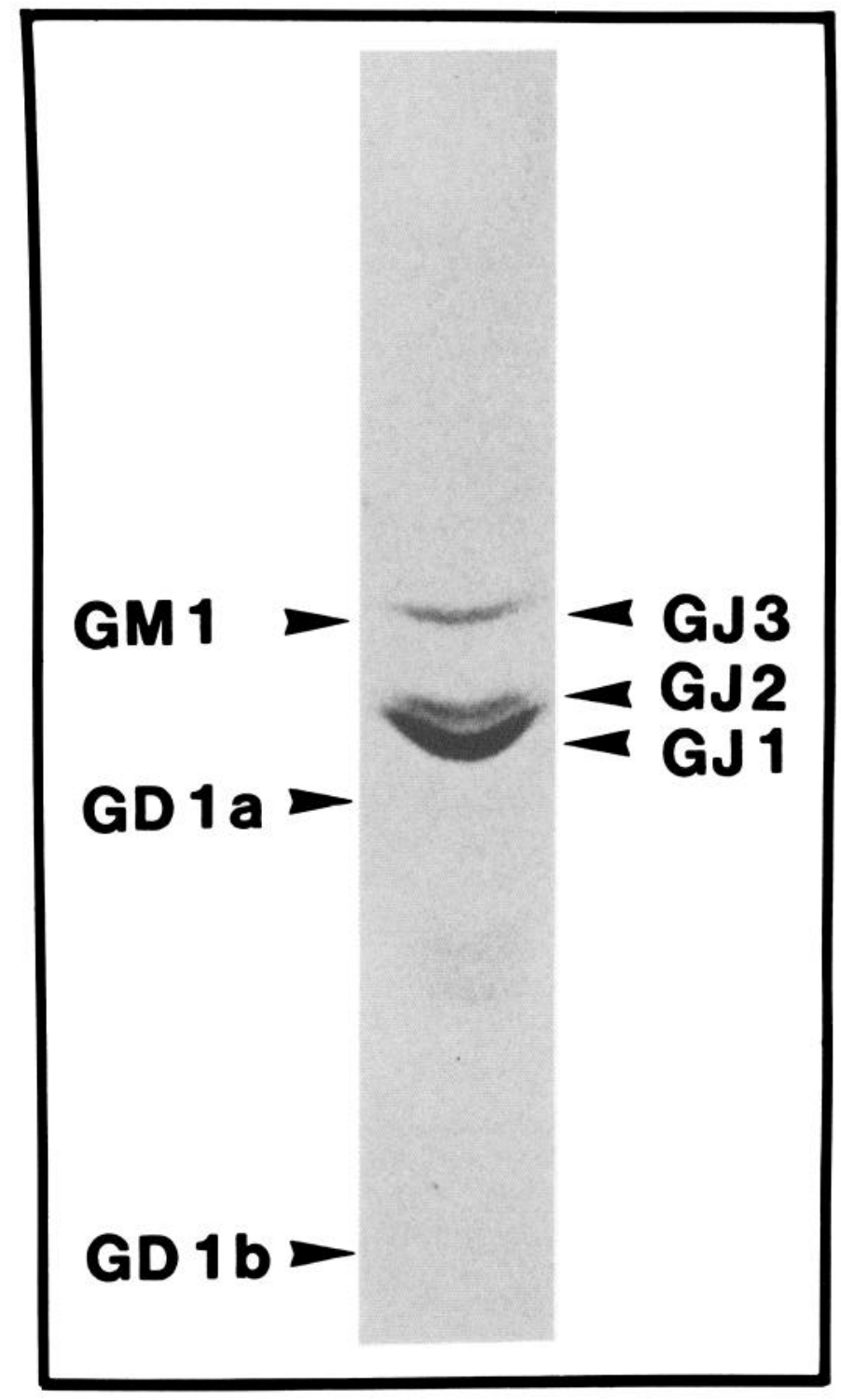

Figure 2. Designation of JONES gangliosides. Enriched gangliosides from rat cerebellum were separated by thin layer chromatography with a solvent system chloroform $/ \mathrm{methanol} / 0.2 \% \mathrm{CaCl}_{2} / \mathrm{H}_{2} \mathrm{O}(50: 45: 10)$. Thereafter, JONES binding gangliosides were identified in an overlay assay with a secondary peroxidase-labeled anti-mouse antibody. Three major bands are recognized by the antibody. The band which migrates fastest is designated GJ3 ("J" for JONES), the intermediate one GJ2 and the slowest one GJ1. GJ3 is positioned at or slightly above GM1; GJ1 is positioned above GD1a approximately in the region of GD3. The third band GJ2 migrates slightly faster than GJ1.

identities of the labeled bands were established by comparison with the migration of purified ganglioside standards. The figure documents 3 major changes in the ganglioside composition of rat forebrain between the E18 and the adult stages. First, there is an increase in the relative amount of GDla during development. Second, the increase in GDla is followed by a delayed increase in GM1. Finally, there is a very pronounced decrease in GD3, which declines below the detection limit after birth. Comparison between the developmental regulation of JONES and that of major tissue gangliosides reveals that the GJ3 time course roughly parallels that of GD3. 


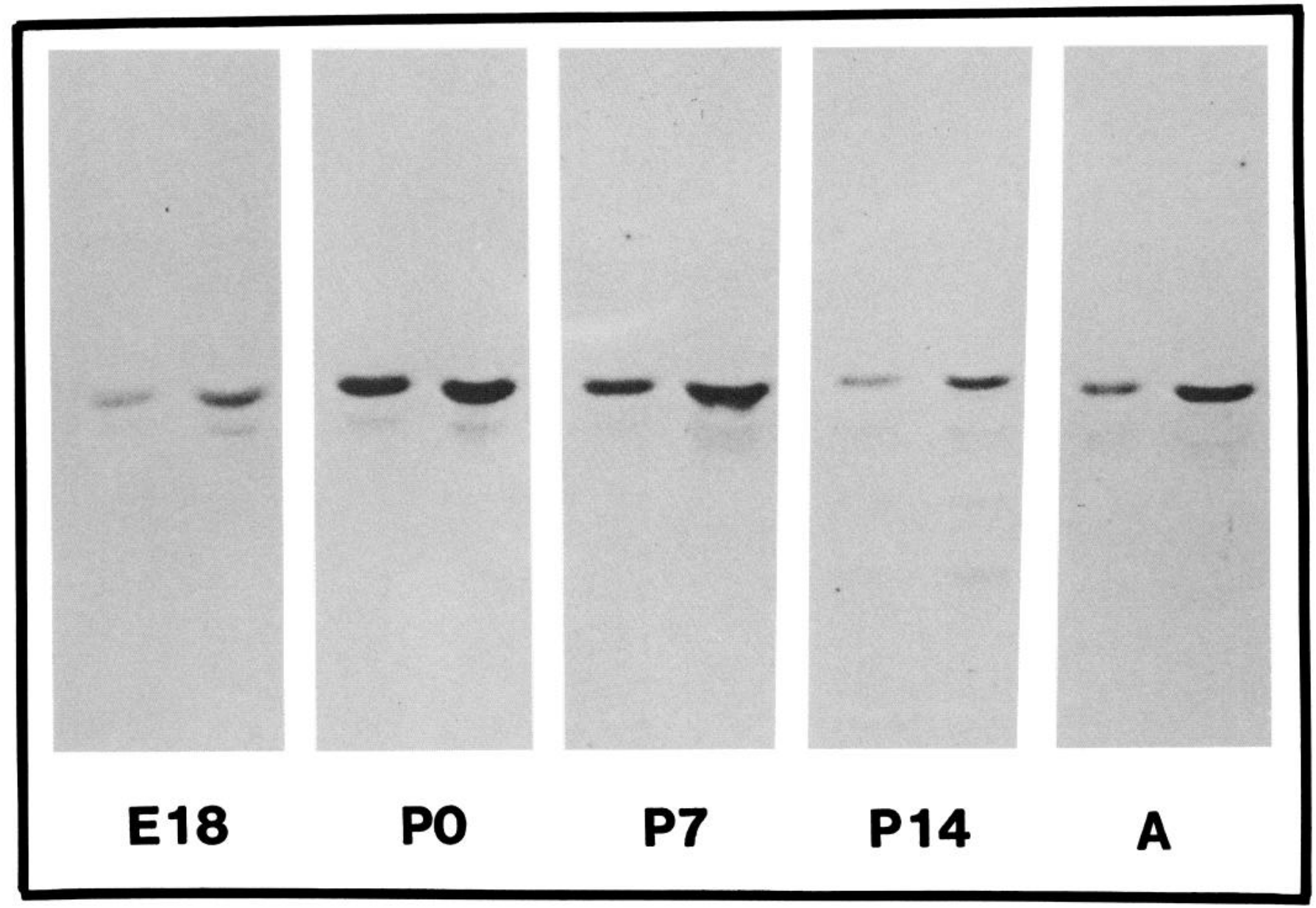

Figure 3. JONES-immunoreactive gangliosides in the retina. Enriched gangliosides from rat retina of embryonic day 18 (E18), postnatal day 0 (P0), P7, P14 and adulthood (A) were subjected to thin-layer chromatography and JONES immunoreactive gangliosides were visualized with the overlay assay. Note that at all stages, including the adult, the upper band (GJ3) predominates. The concentration of JONES gangliosides is maximal after birth. The approximate amount applied for each stage is: 6 microgram sialic acid (left hand lane) and 13 microgram sialic acid (right hand lane). The increased amounts of gangliosides (right hand lanes) facilitate immunodetection but lead to bending and some displacement of the bands. All samples were run on the same chromatogram.

\section{Peripheral nervous system}

Anatomical data showed that JONES immunoreactivity was also present in dorsal root ganglia. To confirm that the immunoreactivity was carried by similar molecules, gangliosides were extracted from ganglia taken at E17, when the immunocytochemical staining is most pronounced. The biochemical assay revealed extremely high concentration of GJ3 in this tissue, along with a less pronounced GJ1 band. The GJ3 of these ganglia was markedly broader than the corresponding band in other nervous system regions (Fig. 7, lane a).

\section{Comparative tissue distribution}

Figure 8 illustrates JONES binding in 1-d-old cultures of cells dissociated from E19 forebrain. It can be seen in these photomicrographs that JONES binding is associated with both cell bodies and cell processes. Consequently, cell perikarya were isolated from tissue in the same way as those used for cultures, shown in Figure 8, and examined to determine whether both JONES immunoreactive bands seen by HPTLC analysis were found on this fraction. Figure $7 b$ shows that both bands were seen in the purified perikarya and were present in a similar ratio to that seen in the whole tissue (Fig. 5a).
The developmental studies of JONES immunoreactivity suggested that the epitope was restricted to essentially the same subset of gangliosides in all regions and at all developmental stages of the rat nervous system. This conclusion was also supported by the several additional analyses represented in Figure 7. Lane $\mathrm{c}$ shows the GJ3 JONES band characteristic of the adult retina. The other lanes show the GJ1 band, which predominates in ganglioside extracts from adult cerebellum (g) as well as in those from the adult forebrain derivatives, olfactory bulb (d), hippocampus (e), and cerebral cortex (f). The slowly migrating bands in lanes $d$ and e of Figure 6 were detected occasionally, but the intensity of the bands varied significantly.

Dot assays of chloroform/methanol extracts of tissue from P2 pups also revealed JONES immunoreactivity in the adrenal gland and in the kidney. The kidney was found to be a very rich source of JONES gangliosides. Thymus, lung, heart, stomach, spleen, liver, intestine, and skeletal muscle showed no detectable specific binding (data not shown).

\section{Discussion}

Biochemical characterization of the JONES epitope

Previous studies suggested that, in retina, the JONES epitope was carried on a ganglioside migrating between GM1 and GM2 

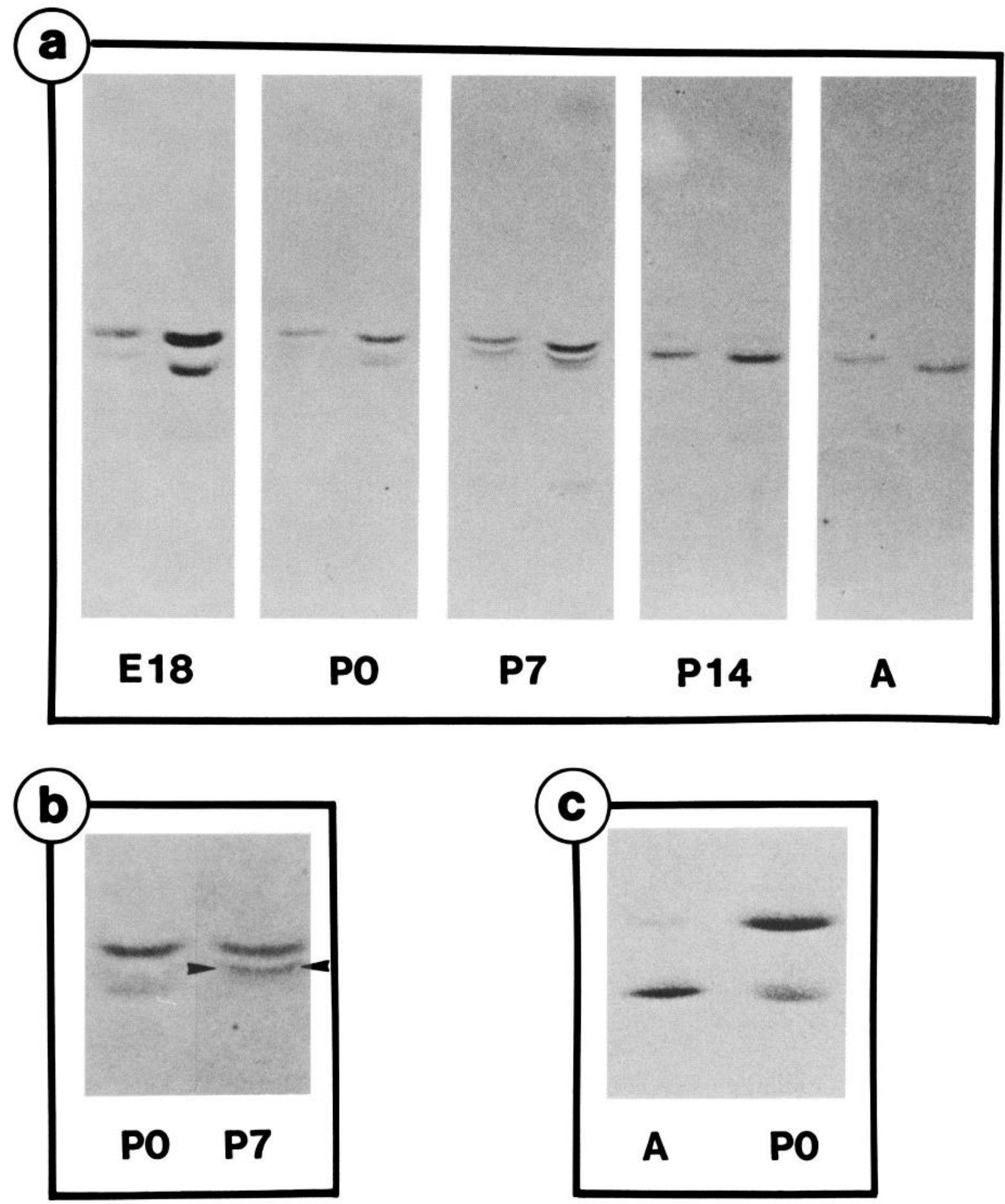

Figure 4. JONES-immunoreactive gangliosides in the cerebellum. Enriched gangliosides from rat cerebella were subjected to thin-layer chromatography and the overlay assay to detect JONES immunoreactivity. $a$, The highest concentration of JONES gangliosides is found at late fetal stages. In the course of cerebellar maturation a shift towards the lower band (GJ1) is observed. $b$, Enlargement of 10-cm-long chromatogram lanes. During the postnatal period the intermediate JONES band (GJ2, arrowheads) becomes pronounced. At earlier and later stages GJ2 is reduced (compare lane P0 and P7 in Fig. $4 b$ and lane A in Fig. 4c). c, Enlargement of 20-cm-long chromatogram lanes. Note the shift from the upper band $(\mathrm{GJ} 3)$ at $\mathrm{P} 0$ to the lower band $(\mathrm{GJ} 1)$ at $A$. At both stages the intermediate band (GJ2) is essentially absent. Samples compared in each individual figure were run on the same plate. Other conventions are the same as in Figure 3.

(Blum et al., 1985; Constantine-Paton et al., 1986). The present work confirms and extends that earlier conclusion. In embryonic forebrain, no JONES reactive bands were found on Western blots, in agreement with our earlier findings with postnatal retina. Essentially no reactive material was found in the residue following chloroform/methanol extraction of tissue, and the
JONES epitope was insensitive to proteolytic digestion but could be destroyed by neuraminidase. It would therefore appear that both at different developmental stages and in different CNS regions most, if not all, the JONES reactive material is in the form of the gangliosides analyzed in the present experiments.

The JONES epitope is carried on a group of 3 gangliosides 

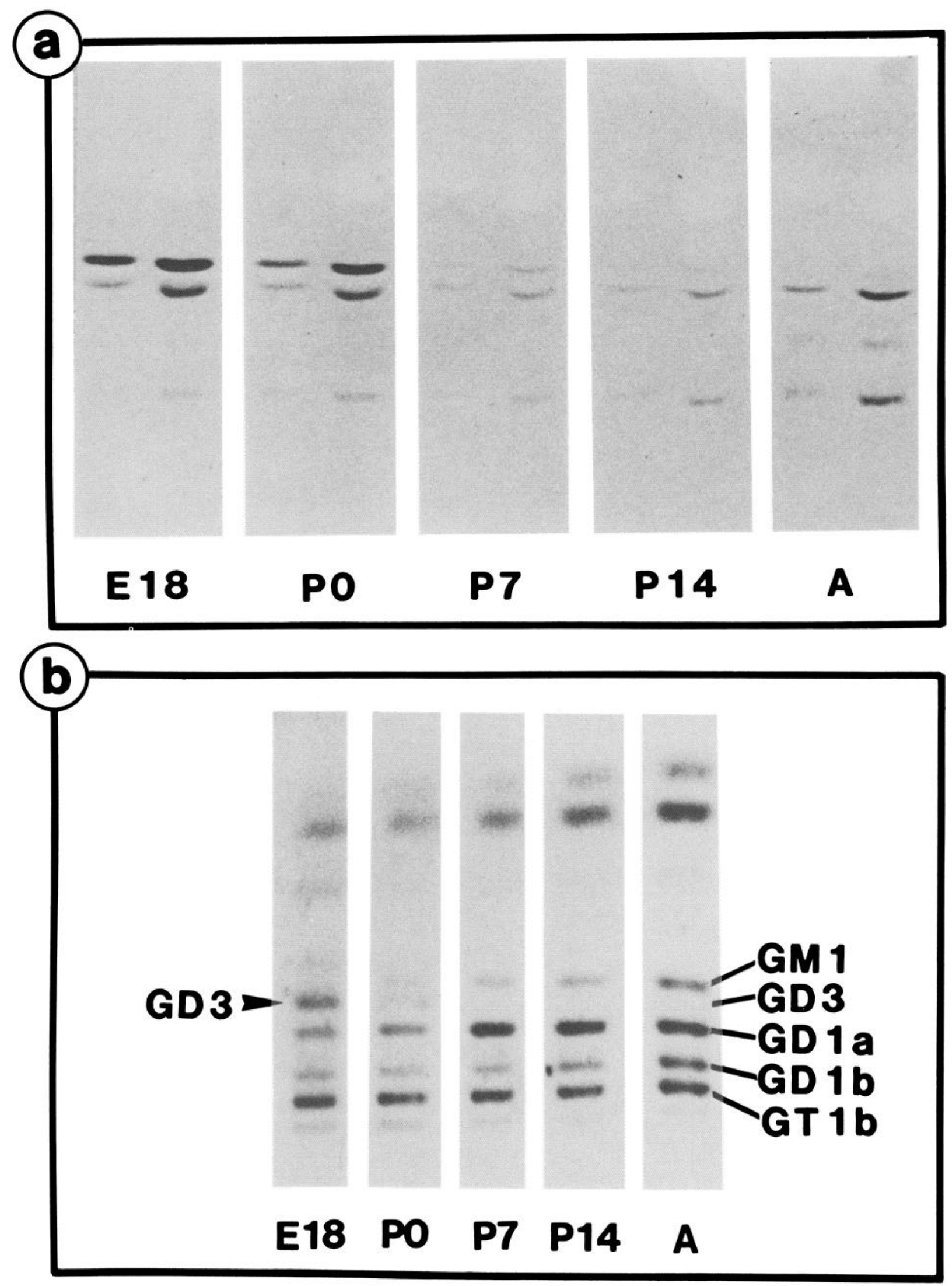

Figure 5. JONES-immunoreactive gangliosides in the forebrain. $a$, JONES gangliosides from rat forebrain preparations identified on HPTLC plates in an overlay assay. The highest concentration of JONES gangliosides is found at late fetal stages where the upper band (GJ3) dominates. During development a shift towards the lower band (GJ1) of the three major JONES gangliosides occurs. As well as the major JONES gangliosides two additional bands were stained in some experiments. Conventions as in Figure 3. $b$, Total ganglioside pattern of forebrain. The development 
that we have labeled for convenience GJ1, GJ2, and GJ3. In addition, we have occasionally seen immunoreactive material migrating in the region of larger polysialogangliosides. Because this material has not been detected consistently, we have not considered it further in the present developmental studies. It may, however, be important in the adult tissue, where it is frequently quite pronounced. The GJ2 band has only been detected in significant amounts in the early postnatal cerebellum. Bccausc of the proximity to GJ1 and of the obscrvation that GJ1 increases when GJ2 decreases, it seems likely that GJ2 represents the same carbohydrate group as G.II but carried on a lipid of different fatty acid composition. Observations on human brain gangliosides indicate that fatty acid chain heterogeneity could account for the broader bands seen in embryonic material as compared with adult samples (Ando and Yu, 1984).

Even though bands of JONES gangliosides are found in all brain regions, it is important to emphasize that the control of expression of these bands differs significantly in the various regions. The relative proportions of the 2 or 3 JONES ganglioside bands, as well as the developmental stage at which they are dominant differ in the 3 areas-retina, forebrain, and cerebellum - in which we have studied them in detail.

The biochemical identity of all of the gangliosides carrying the JONES epitope is not yet certain. The developmental regulation of the JONES immunoreactive gangliosides and major gangliosides in forebrain revealed similarities between the JONES antigens and GD3. Furthermore, using retinal tissue Blum and Barnstable (1986) have shown that the GJ3 band is a basesensitive O-acetylated derivative of GD3. This is the same molecule that has been characterized from human melanoma cells using antibody D1.1. D1.1 was raised against a rat glioma cell line (Cheresh et al., 1984a, b; Levine et al., 1984) and also reacts with gangliosides present in rat brain. It has also been shown (Mendez-Otero et al., 1988) that the staining pattern in tissue sections with both antibodies is very similar. These data suggest that both antibodies are recognizing the same ganglioside antigens. In this context it is relevant to note that 2 ganglioside bands similar to the ones we report here using JONES have been recognized with D1.1 by Cheresh, who used an overlay procedure similar to ours (Cheresh et al., 1984a).

The considerably slower migration of the GJ1 band suggests that it is not a GD3 derivative (R. Yu, personal communication). The JONES epitope on this molecule is also sensitive to neuraminidase and is base labile, suggesting that it is also an acetylated derivative of a ganglioside. It is possible that this band represents an acetylated derivative of a further GD3 metabolite such as GD2 or GT3 (Svennerholm, 1957).

\section{Comparison of immunocytochemical and biochemical data}

The present results show generally good agreement with the immunocytochemical results in the accompanying paper (Mendez-Otero et al., 1988). Thus, in retina and cerebellum, the maximal biochemical expression of JONES immunoreactive gangliosides in the postnatal period and the gradual decrease with maturity correspond well with the histochemical observations. The HPTLC analysis of cerebellum samples shows that

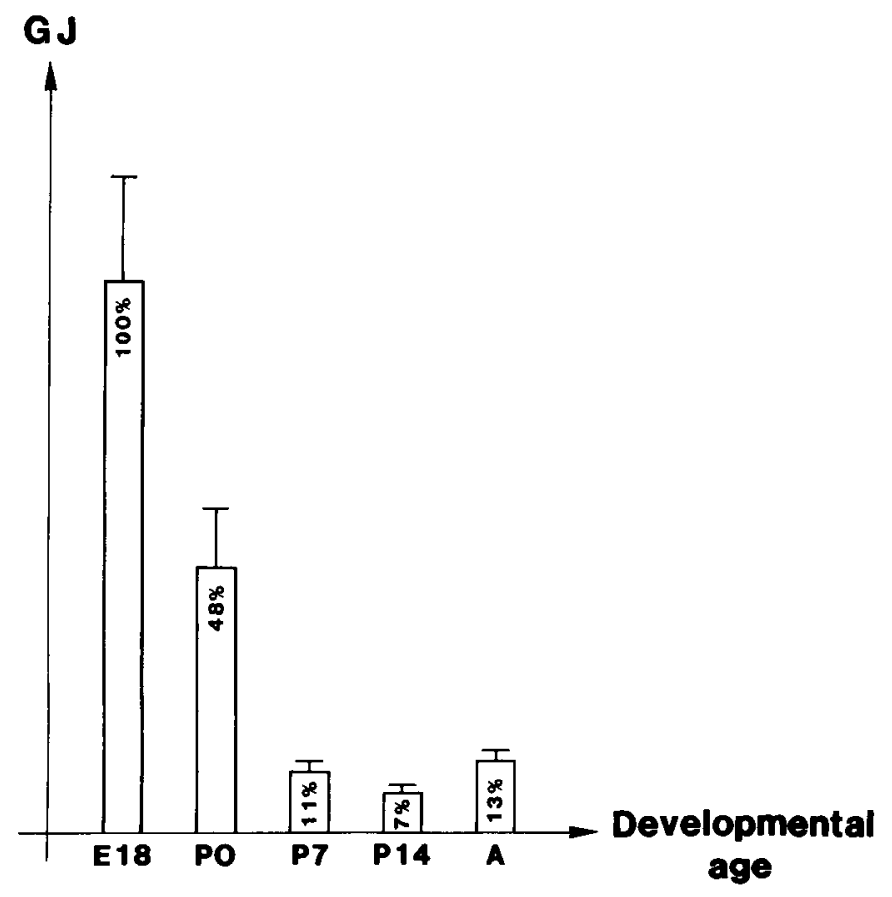

Figure 6. Quantitative evaluation of JONES ganglioside expression. Rat forebrain gangliosides were separated by HPTLC, stained for JONES antigenicity with the overlay assay and scanned densitometrically. The relative amount of JONES gangliosides $(G J=G J 1+G J 2+G J 3)$ from E1 8 forebrain is given the value of $100 \%$. The intensity of JONES binding at other developmental stages was then related to the value at E18. The GJ concentration declines rapidly by one order of magnitude after the first postnatal week compared with late fetal stages. On the other hand, the GJ concentration in adult forebrain is roughly doubled in comparison with P14. Standard deviations out of 5 experiments are given as bars on top of columns.

within the overall quantitative change of JONES epitope expression, other qualitative changes are also occurring. In the embryonic and early postnatal animal, the major immunoreactive band is GJ3. In the adult, the major band is GJ1. It is not yet clear whether the change from GJ3 to GJ1 is a linked process or represents 2 separate molecular, and perhaps functional, events.

Other regions show less agreement between immunocytochemical and biochemical measurements of JONES binding. In the whole forebrain immunocytochemical reactivity of JONES antibody declined to background by the end of the second postnatal week (Mendez-Otero et al., 1988), whereas the biochemical analysis revealed that significant quantities of the JONES gangliosides remained in this region into adulthood.

Such "cryptic" behavior has previously been described for other gangliosides, particularly GD3 (Goldman et al., 1984). The reasons for this behavior remain obscure, but they may involve masking by other membrane components. The membrane solubilization during the ganglioside preparation for biochemical analyses would be expected to destroy these neighbor

$\leftarrow$

of HPTLC plates was performed by the "DE" solvent system (see Materials and Methods). Ganglioside preparations as used in Figure 5a were stained with resorcincol after separation by HPTLC. Note that the GD3 expression parallels the developmental protile of GJ3 (upper JONES band in Fig. 5a). Gangliosides, GM1, GD3, GDla, GD1b, GT1b, are marked in Figure $5 b$ according to the nomenclature of Svennerholm (1980). All samples shown in each figure were run on the same plate. 


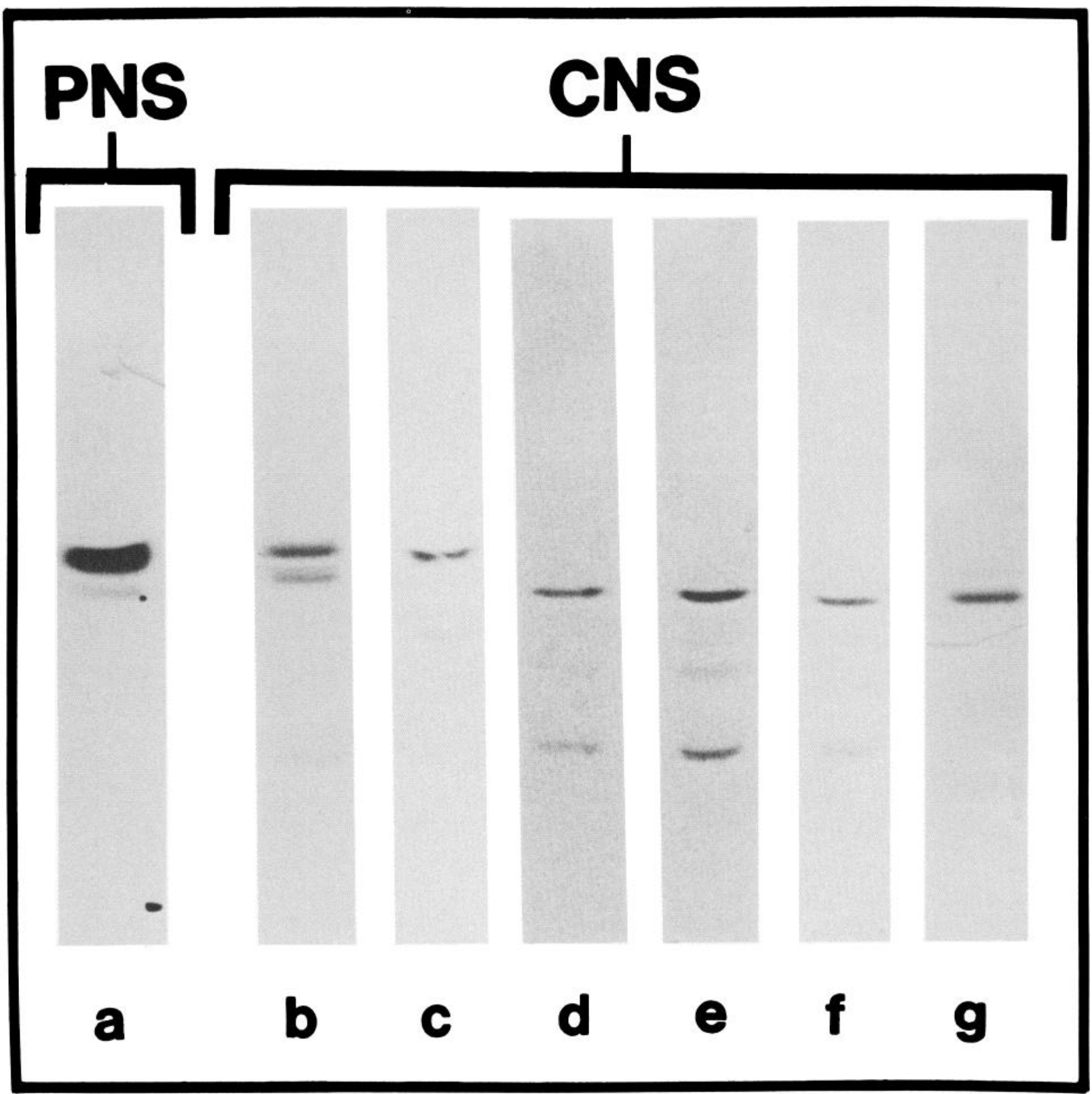

Figure 7. Regional comparisons of JONES gangliosides. Gangliosides from various parts of the PNS and CNS were analyzed by HPTLC and overlay assay. JONES gangliosides were found in all regions investigated. $a$, Particularly high concentrations of JONES gangliosides were present in dorsal root ganglia. $b$, Pure preparations of forebrain cell perikarya without cell processes (E20) display a similar ganglioside pattern as whole forebrain suggesting that the different JONES immunoreactive gangliosides are distributed homogeneously in the membrane of individual cells. $c$, In the adult organism, only in retina is the upper JONES band (GJ3) preserved. This is in contrast to all other regions of the nervous system where the lower band GJ1 dominates: olfactory bulb $(d)$, hippocampus $(e)$, cerebral cortex $(f)$, and cerebellum $(g)$. The approximate amount of sialic acid per lane is $a, 3 \mu \mathrm{g}$ and $b-\mathrm{g}, 7-9 \mu \mathrm{g}$. Samples were run on different HPTLC plates, under identical conditions. The lanes are presented with all the origins aligned.

interactions and render the gangliosides accessible to the antibody. The divergence between immunocytochemical and biochemical measurements of JONES binding only appears to occur in some regions late in development; it is unlikely, therefore, to negate any of the functional hypotheses generated from the anatomical data (Mendez-Otero et al., 1988). Furthermore, it is possible that the same masking that precludes antibody recognition of these small antigens in intact tissue may also serve as an additional means of regulating their developmental function.

\section{Relationship between JONES expression and cell or process migration}

The tissue specificity of JONES gangliosides expression and the observations on qualitative and quantitative changes in different bands during late fetal and postnatal life support the conclusions arrived at independently in the preceding immunocytochemical analyses (Constantine-Paton et al., 1986; Mendez-Otero et al., 1988), namely, that these gangliosides are associated with neurogenetic events involving cell or process movement. For each 


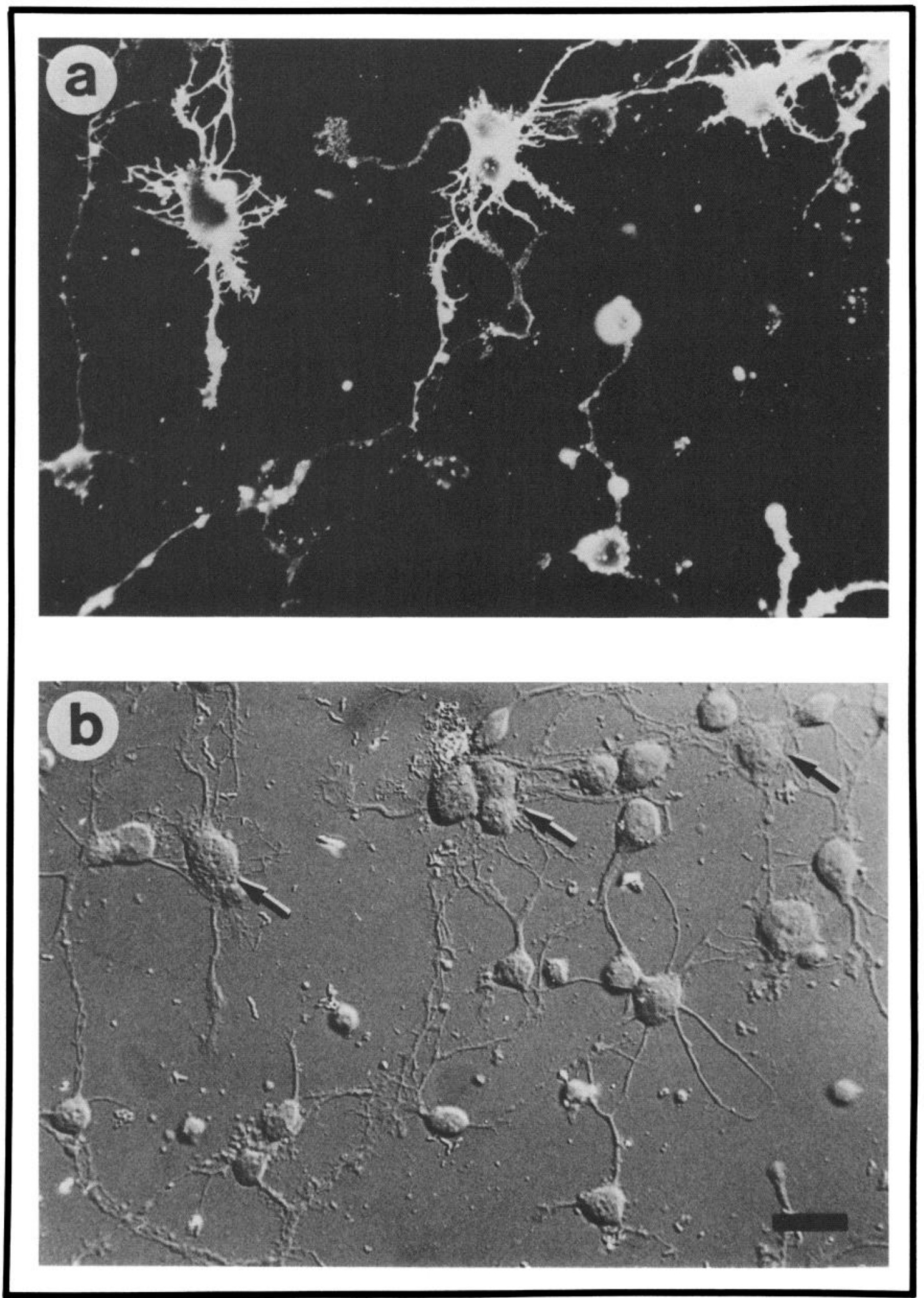

Figure 8. Demonstration of JONES gangliosides on cells somata and cell processes. Cells from E19 rat forebrain cultured for $1 \mathrm{~d}$, incubated for half-hour with JONES antibody, fixed and stained with rhodamine conjugated second antibody. $a$, Immunofluorescence; $b$, differentiated interference contrast of the same field. JONES positive cells comprised approximately $25 \%$ of all cells. Positive cells generally had a cell diameter of more than $10 \mu \mathrm{g}$ and showed complex processes which were also labeled. Arrows mark some of the positive cells. Scale bar, $20 \mu \mathrm{g}$. 
region examined, the biochemical prevalence of the JONES gangliosides relative to the total ganglioside content shows a good correspondence with the periods when cell migrations are most prominent. Accordingly, in retina the majority of neuronal cells migrate to their final positions in the first postnatal week and the process is essentially complete at day 14 , when the eyes open. This is paralleled by changes in JONES immunoreactive gangliosides levels that increase at birth and show a marked decrease at P14 (Fig. 3).

By contrast, in forebrain, where most neuroblast migration occurs prenatally and is complete by the end of the first postnatal week, the peak of JONES antigen expression is similarly shifted to the late fetal and early neonatal period (Figs. 5, 6).

In the cerebellum there are 2 periods of neuroblast migration: an early prenatal period when Purkinje and deep nuclei cells migrate pialward from their subventricular germinal zone and a postnatal period when postmitotic granule cells migrate inward to establish the internal granule cell layer. Both migration periods are accompanied by a pronounced expression of JONES gangliosides. Moreover, the inward migration from the external granular layer is unusual in the development of the CNS, and it is accompanied by a similarly unusual dominance of the GJ2 band. This raises the possibility that the relative attractiveness of potential migratory pathways within the same microenvironment may be modulated by the proportions of the different JONES gangliosides present on the various cellular substrates.

\section{Potential functional role of the JONES gangliosides}

Gangliosides have been associated with a wide variety of cellular functions, many of which are likely to occur during neurogenesis. The immunocytochemical and biochemical evidence outlined above and in preceding publications suggests that the JONES antigens in the developing rat brain most consistently colocalized with migratory activity of cells and cell processes.

One likely prerequisite of effective migratory activity is adhesion, and gangliosides have been frequently implicated as modulators of both cell-to-substratum and cell-to-cell adhesion processes. For example, the widely distributed extracellular matrix protein fibronectin possesses a strong ganglioside binding site, which is separate from the region of the molecule that binds to its cell membrane receptor (Thompson et al., 1986). The ability of ganglioside-deficient transformed fibroblasts to organize strands of fibronectin on their surface can be restored by exogenous gangliosides (Spiegel et al., 1984). In addition, at both the light and the electron microscope level, disialogangliosides have been associated with the adhesive contacts of human melanoma cells (Cheresh and Klier, 1986) and antibodies to these gangliosides disrupt the substrate adhesion of both melanoma and neuroblastoma cells in tissue culture (Cheresh et al., 1986).

Cell-cell adhesion has also been shown to be influenced by gangliosides. Neural cells have been shown to adhere to immobilized gangliosides but not to other glycolipids, which suggests that such adhesion involves a specific ganglioside epitope and not a more general ionic or hydrophobic interaction. This adhesion is considerably attenuated, however, by pretreatment of the cells with trypsin, which suggests that the ganglioside interaction is mediated through a cell membrane protein that functions as the actual receptor (Blackburn et al., 1986).

How then could the JONES gangliosides be involved in the adhesion systems underlying neuronal cell and axon migration? It seems likely, given the precedents mentioned above, that these glycolipids work in association with some extracellular matrix or cell membrane protein. Possible candidates might be the extracellular matrix protein laminin, which appears to be an effective growth substrate for dorsal root ganglion cell and retinal ganglion cell axons (see Letourneau, 1985), or cell adhesion molecules such as N-CAM, Ng-CAM, or L1 or NILE and cadherins (Salton et al., 1983; Grumet et al., 1983; Schachner et al., 1983; Rathjen and Schachner, 1984; Hatta et al., 1985). Like $\mathrm{N}-\mathrm{CAM}$, the JONES immunoreactive gangliosides show changes from embryonic to adult forms and at one stage in the chick retina N-CAM shows a central to peripheral gradient similar to the first appearance of JONES binding in E13 rat retina (Rutishauser et al., 1985; Constantine-Paton et al., 1986). Changes in JONES immunoreactive species occur in the cerebellum at the time of granule cell migration, which is also the time at which Ng-CAM or L1 or NILE is expressed (Schachner et al., 1983; Daniloff et al., 1986). Because of their known calcium binding ability (Abramson et al., 1982), gangliosides may play a modulatory role for other adhesion molecules, such as cadherin, that show a calcium dependence in both their adhesion and their sensitivity to proteolytic cleavage from cell surfaces (Hatta et al., 1985; see also Cheresh and Klier, 1986).

The application of antibody technology to investigations of the developing brain has produced a number of other immunological probes for glycolipid antigens. A number of these, including antigen 7A and SSEA-1, that contain the X-determinant trisaccharide (Lagenaur et al., 1983; Yamamoto et al., 1985), the antigen recognized by anti-ganglioside antibody Q2 11 (Henke-Fahle, 1983; Rohrer et al., 1985; Rosner et al., 1985), and the groups of gangliosides recognized by antibody 18B8 (Grunwald et al., 1985; Dubois et al., 1986) show discrete patterns of labeling in the developing nervous system.

Thus, there is increasing evidence that lipids bearing carbohydrate epitopes, as defined by monoclonal antibodies, can be distributed in very discrete spatial and temporal patterns in the developing nervous system. In addition to novel patterns produced by addition of whole sugar residues, it is now apparent that additional specificity can be conferred by the modification of the carbohydrates by mechanisms such as acetylation (Cheresh et al., 1984a, b). By interacting with other components of the cell surface, these small molecules could convey a degree of both spatial and temporal selectivity to pathways of cell and axon migration that are only broadly defined by more generally distributed molecules such as cell-adhesion proteins.

\section{References}

Abramson, M. B., R. K. Yu, and V. Zaby (1982) Ionic properties of beef brain gangliosides. Biochem. Biophys. Acta 280: 365-372.

Ando, S., and R. K. Yu (1984) Fatty acid and long-chain base composition of gangliosides isolated from adult human brain. J. Neurosci. Res. 12: 205-211.

Barbera, A. J. (1975) Adhesive recognition between developing retinal cells and the optic tecta of the chick embryo. Dev. Biol. 46: 167-191.

Barbera, A. J., R. B. Marchase, and S. Roth (1973) Adhesive recognition and retinotectal specificity. Proc. Natl. Acad. Sci. USA 70: 2481-2486.

Barnstable, C. J. (1982) Immunological studies of the retina. In Neuroimmunology, J. Brocks, ed., pp. 183-214, Plenum, New York.

Blackburn, C. C., P. Swank-Hill, and R. L. Schnaar (1986) Gangliosides support neuronal retina cell adhesion. J. Biol. Chem. 261:28732881 .

Blum, A. S., and C. J. Barnstable (1986) Structure and regulation of a developmentally restricted neuronal surface antigen. J. Cell Biol. 103: $231 \mathrm{a}$.

Blum, A. S., M. Constantine-Paton, and C. J. Barnstable (1985) A 
developmentally regulated ganglioside in the rat central nervous system. Proc. Soc. Neurosci. 11: 1064.

Cheresh, D. A., and F. G. Klier (1986) Diasialoganglioside GD2 distributes preferentially into substrate-associated microprocesses on human melanoma cells during their attachment to fibronectin. J. Cell Biol. 102: 1887-1897.

Cheresh, D. A., R. A. Reisfeld, and A. P. Varki (1984a) O-acetylation of diasialoganglioside GD3 by human melanoma cells creates a unique antigenic determinant. Science 225: 844-846.

Cheresh, D. A., A. P. Varki, N. M. Varki, W. B. Stallcup, J. Levine, and R. A Reisfeld (1984b) A monoclonal antibody recognizes an $\mathrm{O}$-acetylated sialic acid in a human melanoma-associated ganglioside. J. Biol. Chem. 259: 7453-7459.

Cheresh, D. A., M. D. Pierschbacher, M. A. Herzig, and K. Mujoo (1986) Disialogangliosides GD2 and GD3 are involved in the attachment of human melanoma and neuroblastoma cells to extracellular matrix proteins. J. Cell Biol. 102: 688-696.

Constantine-Paton, M., A. S. Blum, R. Mendez-Otero, and C. J. Barnstable (1986) A cell surface molecule distributed in a dorsoventral gradient in the perinatal rat retina. Nature 324: 459-462.

Daniloff, J. K., C.-M. Chuong, G. Levi, and G. M. Edelman (1986) Differential distribution of cell adhesion molecules during histogenesis of the chick nervous system. J. Neurosci. 6: 739-758.

Dreyfus, H., P. F. Urban, S. Harth, A. Preti, and P. Mandel (1976) Retinal gangliosides: Composition, evolution with age. Biosynthetic and metabolic approaches. In Ganglioside Function, G. Porcellati, B. Ceccarelli, and G. Tettamanti, eds., pp. 163-186, Plenum, New York.

Dubois, C., J. L. Magnani, G. B. Grunwald, S. L. Spitalnik, G. D. Trisler, M. Nirenberg, and V. Ginsburg (1986) Monoclonal antibody 18B8, which detects synapse-associated antigens, binds to ganglioside $\mathbf{G}_{\mathrm{r}_{3}}$ $\left(\mathrm{II}^{3}(\mathrm{NeuAc})_{3}\right.$ Lac Cer). Proc. Natl. Acad. Sci. USA 261: 3826-3830.

Fekete, D. M., and C. J. Barnstable (1983) Subcellular localization of rat photoreceptor-specific protein. J. Neurocytol. 12: 785-803.

Folch, J., M. Lees, and G. H. Sloan-Stanley (1957) A simple method for the isolation and purification of total lipides from animal tissue. J. Biol. Chem. 226: 497-509.

Goldman, J. E., M. Hirano, R. K. Yu, and T. N. Seyfried (1984) GD3 ganglioside is a glycolipid characteristic of immature neuroectodermal cells. J. Neuroimmunol. 7: 179-192.

Gorio, A., P. Marini, and R. Zanoni (1983) Muscle reinnervation. III. Motoneuron sprouting capacity, enhancement by exogenous gangliosides. Neuroscience $8:$ 417-429.

Gorio, A., D. Janigro, and R. Zanoni (1985) Neuritogenesis and regeneration in the nervous system: An overview of the problem and on the promoting action of gangliosides. In Ganglioside Structure, Function and Biomedical Potential, R. W. Leeden, R. K. Yu, M. M. Rapport, and K. Suzuki, eds., pp. 465-473, Plenum, New York.

Grumet, M., U. Rutishauser, and G. M. Edelman (1983) Neuron-glia adhesion is inhibited by antibodies to neural determinants. Science 222: 60-62.

Grunwald, G. B., P. Fredman, J. L. Magnani, D. Trisler, V. Ginsburg, and $M$. Nirenberg (1985) Monoclonal antibody 18B8 detects gangliosides associated with neuronal differentiation and synapse formation. Proc. Natl. Acad. Sci. USA 82: 4008-4012.

Hakamori, S. (1981) Glycosphingolipids in cellular interaction, differentiation, and oncogenesis. Annu. Rev. Biochem. 50: 733-764.

Hatta, K., T. M. Okada, and M. Takeichi (1985) A monoclonal antibody disrupting $\mathrm{Ca}^{++}$dependent cell-cell adhesion of brain tissue: Possible role of its target antigen in animal pattern formation. Proc. Natl. Acad. Sci. USA 82: 2789-2793.

Hefti, F., J. Hartikka, and W. Frick (1985) Gangliosides alter morphology and growth of astrocytes and increase the activity of choline acetyltransferase in cultures of dissociated septal cells. J. Neurosci. 5: 2086-2094.

Henke-Fahle, S. (1983) Monoclonal antibodies recognized gangliosides in the chick brain. Neurosci. Lett. 14: 160.

Laemmli, U. (1970) Cleavage of structural proteins during the assembly of the head of bacteriophage T4. Nature 227: 680-685.

Lagenaur, C., F. Rathjen, F. Linder, J. Weber, and M. Schachner (1983) Antigens of mouse central neurons: New markers for cell subclasses and function. J. Neurochem. 44:5147.

Letourneau, P. (1985) Guidance of neurite outgrowth by pathways of substratum-adsorbed laminin. J. Neurosi. Res. 13: 213-220.

Levine, J. M., L. Beasley, and W. B. Stallcup (1984) The D1.1 antigen:
A cell surface marker for germinal cells of the central nervous system. J. Neurosci. 4: 820-831.

Marchase, R. B. (1977) Biochemical investigations of retino-tectal adhesive specificity. J. Cell Biol. 75: 237-257.

Mendez-Otero, R., B. Schlosshauer, and M. Constantine-Paton (1986) JONES binding gangliosides are associated with regions of cell and process migration in the developing CNS. Soc. Neurosci. Abstr. 12: 317.

Mendez-Otero, R., B. Schlosshauer, C. J. Barnstable, and M. Constantine-Paton (1988) A developmentally regulated antigen associated with neural cell and process migration. J. Neurosci. 8: 564-579.

Molday R. S., and D. MacKenzie (1983) Monoclonal antibodies to rhodopsin: Characterization, crossreactivity and application as structural probes. Biochemistry 22: 653-660.

Rathjen, F. G., and M. Schachner (1984) Immunocytological and biochemical characterization of a new neuronal cell surface component ( $\mathrm{Ll}$ antigen) which is involved in cell adhesion. EMBO J. 3: 110.

Rohrer, H., S. Henke-Fahle, T. El-Sharkawy, H. D. Lux, and H. Thoenen (1985) Progenitor cells from embryonic chick dorsal root ganglia differentiate in vitro to neurons: Biochemical and electrophysiological evidence. EMBO J. 4: 1709-1714.

Rosner, H. (1980a) A new thin-layer chromatographic approach for separation of multisialogangliosides. Anal. Biochem. 109: 437-442.

Rosner, H. (1980b) Ganglioside changes in the chicken optic lobes and cerebrum during embryonic development. W. Roux's Arch. 188: 205-213.

Rosner, H., M. Alaqtum, and H. S. Henkefah (1985) Developmental expression of GD3 and polysialogangliosides in the embryonic chicken nervous tissue reacting with monoclonal antiganglioside antibodies. Dev. Brain Res. 18: 85-95.

Rutishauser, U., M. Watanabe, J. Silver, F. A. Troy, and E. R. Vimr (1985) Specific alteration of NCAM-mediated cell adhesion by an endoneurominidase. J. Cell Biol. 101: 1842-1849.

Saito, M., N. Kasai, and R. K. Yu (1985) In situ immunological determination of basic carbohydrate structures of gangliosides on thin-layer plates. Anal. Biochem. 148: 54-58.

Salton, S. R., C. Richter-Landsberg, L. A. Green, and M. L. Schelanski (1983) Nerve growth factor inducible large external (NILE) glycoprotein: Studies of a central and peripheral neuronal marker. J. Neurosci. 3: 441-454.

Schachner, M., A. Faissner, J. Kruse, J. Linder, D. H. Meier, F. G. Rathjen, and H. Wernecke (1983) Cell-type specificity and developmental expression of neural cell surface components involved in cell interactions and structurally related molecules. Cold Spring Harbor Symp. Quant. Biol. 48: 557-568.

Schlosshauer, B., R. Mendez-Otero, and M. Constantine-Paton (1986) Developmental regulation of JONES gangliosides in the mammalian nervous system. Soc. Neurosci. Abstr. 12: 317

Schwartz, M., and N. Spirman (1982) Sprouting from chicken embryo dorsal root ganglia induced by nerve growth factor is specifically inhibited by affinity purified antiganglioside antibodies. Proc. Natl. Acad. Sci. USA 79: 6080-6083.

Seifert, W. (1981) Gangliosides in nerve cell cultures. In Gangliosides in Neurological and Neuromuscular Function, Development and Repair, M. M. Rapport and A. Gorio, eds., pp. 99-117, Raven, New York.

Sparrow, J. R., and B. Grafstein (1982) Sciatic nerve regeneration in ganglioside-treated rats. Exp. Neurol. 77: 230-235.

Spiegel, S., J. Schlessinger, and P. H. Fishman (1984) Incorporation of fluorescent gangliosides in to human fibroblasts: Mobility, fate, and interaction with fibronectin. J. Cell Biol. 99: 699-704.

Spirman, N., B.-A. Sela, and M. Schwartz (1982) Antiganglioside antibodies inhibit neuritic outgrowth from regenerating goldfish retinal explants. J. Neurochem. 39: 874-877.

Svennerholm, L. (1957) Quantitative estimation of sialic acid. II. A colorimetric resorcinol-hydrochloride acid method. Biochim. Biophys. Acta 24: 604-611.

Svennerholm, L. (1980) Ganglioside designation. In Structure and Function of Gangliosides, L. Svennerholm, P. Mandel, H. Dreyfus, and P. F. Urban, eds., pp. 11-13, Plenum, New York.

Thompson, L. K., P. M. Horowitz, K. L. Bentley, D. D. Thomas, J. F. Alderete, and R. J. Klebe (1986) Localization of the gangliosidebinding site of fibronectin. J. Biol. Chem. 261: 5209-5214.

Toffano, G., G. E. Savoini, F. Moroni, G. Lombardi, L. Calza, and L. 
F. Agnati (1984) GM1 ganglioside stimulates the regeneration of dopaminergic neurons in the central nervous system. Brain Res. 261: 163-166.

Tsuji, S., M. Arita, and Y. Nagai (1983) GQ1b, a bioactive ganglioside that exhibits novel nerve growth factor (NGF)-like activities in two neuroblastoma cell lines. J. Biochem. 94: 303-306.

Warren, L. (1959) The thiobarbituric assay of sialic acid. J. Biol. Chem. 234: 1971-1975.
Willinger, M., and M. Schachner (1980) GMl ganglioside as a marker for neuronal differentiation in mouse cerebellum. Dev. Biol. 74: 101117.

Yamamoto, M., A. M. Boyer, and G. A. Schwarting (1985) Fucosecontaining glycolipids are stage- and region-specific antigens in the developing embryonic brain of rodents. Proc. Natl. Acad. Sci. USA 82: 3045-3049. 